\title{
A Novel Approach for Identification of Forest Fires using Land Surface Temperature Images
}

\author{
${ }^{1}$ Buyyani Lavanya, ${ }^{2}$ B.Padmaja \\ Vardhaman College of Engineering, Hyderabad, India
}

\begin{abstract}
Forest fire is those of the natural disasters that cause devastation to economy and environment. In order determine forest fire many of the detecting approaches have been applied. In this paper, we proposed an approach for detecting forest fire by using land surface temperature satellite imagery. An image processing technique carried out on to identify the regions of interest extracted and mean wavelengths from these images. If the wavelength is greater than 31.8, it treated as forest fire. This approach uses $k$ - mean clustering for segment the images and Haar wavelet transforms coefficient selection is used to modified decomposition of feature extracted regions to get more accuracy.
\end{abstract}

Keywords: Forest fire; Wavelet coefficient selection; Image processing; k-means clustering; Surface temperature satellite imagery; Temperature scale

\section{Introduction}

Forest is a renewable resource for human existence and sustainability of the biodiversity. Forests are natural home to great majority of terrestrial creatures, including early man as it can provide the basic needs of species survival - water, food, and shelter. Human activities and natural disasters, forests have been contributes to forest destruction, which badly damages the forest eco-system, economy and devastation to life and property. Forest fire is considered to be one of the most deforestation natural disasters affecting the society, environment and economy widely.

Forests occupy around 31 percent land area of the world. Forests contributes about 1\% of world GDP (Gross Domestic Products) thus forming a good source of income to the government. Forest area is increased globally, either through planting or natural processes at some regions. In this century, the rate of deforestation is increased when compare to previous, but still, a disturbingly high 13 million hectares were varnished yearly.

Forest fires are one of the major natural and manmade hazards which show more effects on species of biodiversity include wild life, environment and also on humans. Fires show a positive as well as negative impact on forests, and its positive impact on forest health varies greatly in different ecosystems, environment, society and economy. Forest fires represent a constant threat to ecological systems, infrastructure and human lives. Fires play a remarkable role in determining landscape structure, pattern and eventually the species composition of ecosystems. When a forest is burnt, causing an increase Carbon dioxide concentration in the atmosphere and also degrades absorption rate. Carbon dioxide contributes to the atmospheric pollution, global warming and greenhouse effect. Soil erosion may take place when after forest fire. Transpiration process of atmosphere also effected by fires. The normal temperatures of the forest is $4^{\circ} \mathrm{C}$ to $10^{\circ} \mathrm{C}$ and low temperatures from $-10^{\circ} \mathrm{C}$ to $-6^{\circ} \mathrm{C}$ but they can also have high temperatures around $20^{\circ} \mathrm{C}$ to $27^{\circ} \mathrm{C}$. In forests, the fuel is provided by trees and bushes. The different causes of forest fires can be characterized into two categories: natural (which are may not control) and human related (which are controllable by FJM). Most forest fires are due to human activities than with natural causes. The present situation has stimulated examining alternative forest fire detection systems. Various approaches are used by many researchers to detect early forest fire. The application of new technologies to forest surveillance and fire detection and monitoring has motivated the development of a considerable variety of forest fire detection and monitoring systems. Several satellite-based automatic fire detection and monitoring systems have been developed. Some approaches are to detect the smoke distribution based on visual cameras. Visual based methods operate on daytime and the accuracy in locating the fire is lower than in the case of infrared detection.

Turgay Celik, Huseyin Ozkaramanl1, and Hasan Demirel[1] proposed new methods for fire and smoke detection using image processing. The approach use different color models for both fire and smoke. The extracted models can be used in complete fire/smoke detection system which combines color information with motion analysis. Color models are created on images to detect fire and smoke. RGB color space in order to detect possible fire-pixel or smoke-pixel candidates can be transformed into $\mathrm{YCbCr}$ color space and analysis can be performed. The detection of fire is carried out using the $\mathrm{YCbCr}$ samples observed that the fire samples show some deterministic characteristics in their color channels of $\mathrm{Y}, \mathrm{Cb}$, and $\mathrm{Cr}$. For smoke detection, model the smoke pixels. But the smoke pixels do not show chrominance characteristics like fire pixels. Smoke detection is out of scope of proposed one. YCbCr color space outperforms other color spaces both in correct detection rate and false alarm rate. For fire detection, the concepts from fuzzy logic are used to replace existing heuristic rules and make the classification more robust in effectively discriminating fire and fire like colored objects. We propose a novel approach for forest fire identification by use of land surface temperature images obtained from NASA earth observation satellite. Abnormalities in temperature distribution are extracted from those images. The entire model is consists of the following : first read the image from satellite , then using $\mathrm{k}$ means algorithm image can segmented into clusters and the region of interest is separated. In process of detecting fire, haar wavelet coefficient selection is applied at level to compute mean wavelength. If the mean wavelength exceeds a value of 31.8 , it is identified as a forest fire.

The rest of the paper is organized as follows. 
Section II describes relevant work, and Section III describes experimental methodology. Section IV focus on results obtained from research, Section V concludes the paper and finally, Section VI discusses the future enhancements that can be applied to the present work.

\section{Relevant Work} fire detection.

The proposed research has been motivated by several earlier researches in the literature related to forest

Forest fire detections are being the research domain for several years. Several researchers contributed their related work to detect forest fire.

Turgay Çelik, Huseyin Ozkaramanli and Hasan Demirel [1] proposed a model to detect fire and smoke based on color models using image processing. T. Hame and Y. Rauste [2] uses multitemporal data to monitor the fire. M.D Flannigan and T.H Vonder Haar [3] describes monitoring forest fire using NOAA satellite AVHRR to identify the fire. Yasar Guneri Sahin and Turker Ince [4] a radio-acoustic sounding system with fine space and time resolution capabilities for continuous monitoring and early detection of forest fires is proposed. Koji Nakau and Masami Fukuda [5] comparison of based on MODIS satellite imagery, and of NOAA satellite imagery with fire fighters' information. J.L. Casanova, A. Calle, A. Romo and J. Sanz [6] proposed a method for large forest fire detection and monitoring by means of an integrated modis-msg system. K. Angayarkkani and Dr. N. Radhakrishnan [7] presented an intelligent system to detect the presence of forest fires in the forest spatial data using artificial neural networks. Radomir S. Stankovi and Bogdan J. Falkowski [8] discuss the haar wavelet transform, different generations and efficient symbolic calculation of haar spectrum. J. R. Martinez - De Dios and A. Ollero [9] given some sensors and communication systems with potential applicability in forest fire fighting and it describes some fire detection and monitoring systems on satellite platforms, on aerial platforms and on ground stations. It include False alarm reduction tool. Damir Krstinic, Darko Stipanicev and Toni Jakovcevic [10] proposed a histogram based forest fire detection using smoke. Wright D.B., T. Yotsumata and N. El-Sheimy[11] proposed a model to identifies and locate forest fire hotspots using thermal images. Jerome Vicente and Philippe Guillemant [12] proposed an approach using smoke images of forest to detect forest fire using temporal algorithm. Junguo Zhang, Wenbin LI, Ning Han and Jiangming Kan [13] design of a system for detection of temperature and humidity and smoke for the prevention of forest fires using ZigBee wireless sensor networks technique to detect forest fire. Nuria Utande Gonzalez de la Higuera and Juan Carlos Garcia Seco [14] developed a software which detects and extinguish wildfires using different methodologies. Zhong Zhang, Jianhui Zhao, Dengyi Zhang, Chengzhang Qu, Youwang Ke and Bo Cai [15] proposed a method which uses the FFT and wavelets to identification of forest fire. Z. Li, S. Nadon and J. Cihlar [16] proposed a fire detection algorithm to monitor the fires using AVHRR (Advanced very high resolution radiometer) images. Suman Tatiraju and Avi Mehta [17] have given an approach to segment the image using K-means clustering. Khaled Alsabti, Sanjay Ranka and Vineet Singh [18] also have given an efficient K-means clustering algorithm to cluster an image. Siddheswar Ray and Rose H. Turi [19] proposed an approach to determine number of clusters in image segmentation. Narasimha Prasad, Rajkumar Gatadi Bandi, and B Padmaja [20] proposed an approach to detect forest fire by monitoring and extracting abnormalities in temperature of images and uses haar wavelet transform.

The previous proposed approach for detection of forest fire was done by smoke images, thermal images, sounding systems, wireless sensor network, and sensor detecting systems. The present research for detecting forest fire using land surface temperature satellite images using K-Means clustering algorithm for segment region of interest followed by haar wavelet transforms and coefficient selection is used to modified decomposition.

\section{Experimental Methodology}

The proposed system for effective detection of forest fires is presented in this section. The objective of this present real time processing of satellite image is to extract temperature distribution for the identification of forest fires. The real time detection system procedure applied in the analysis is shown in Fig.1. The input for this system is a land surface temperature image with noise or without noise.

The satellite images obtained may contain noise. When processed image with noise then the value obtained is different from value obtained from original image. It may leads to less accuracy. The original satellite land surface temperature image contains various colors analyzed based on temperature scale where each spectrum range represents a particular temperature value. These spectral ranges must be separated to differentiate between high and low temperatures. Here, temperature scale is used to identify the range of temperatures by using color factor, shown in Fig. 2. 


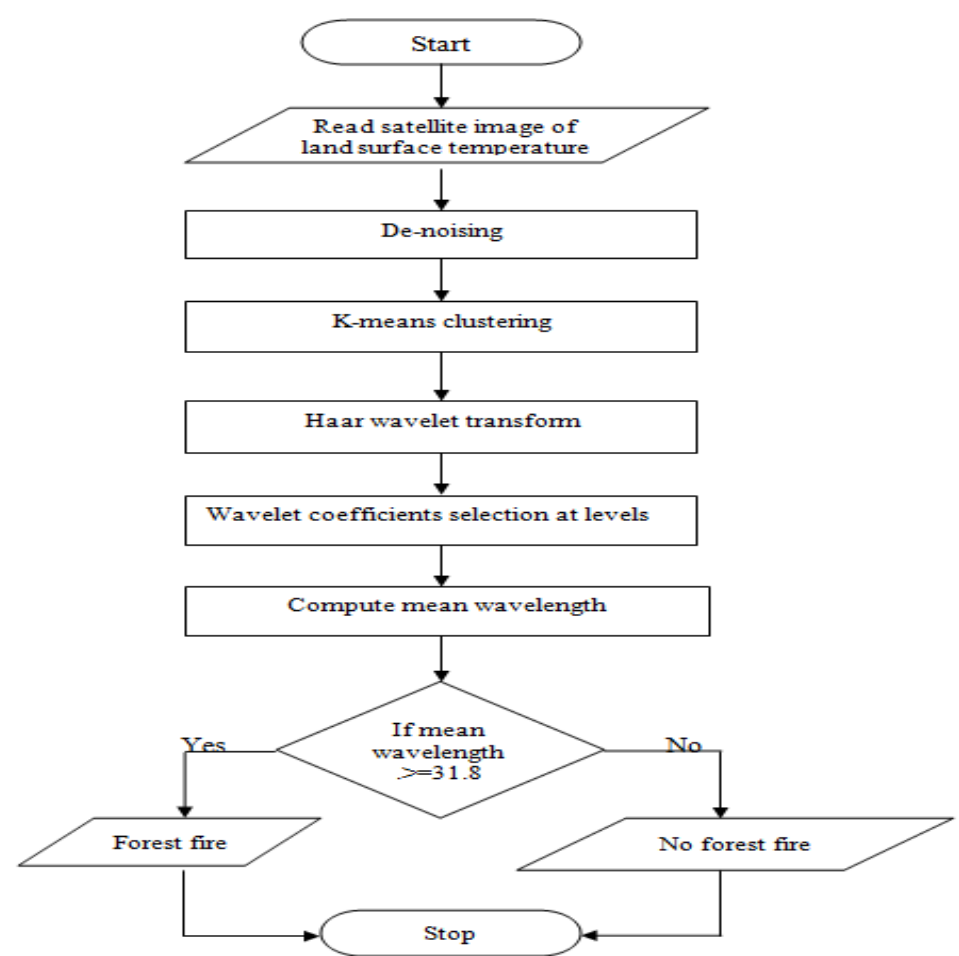

Figure 1: Detection of Forest fire in real time

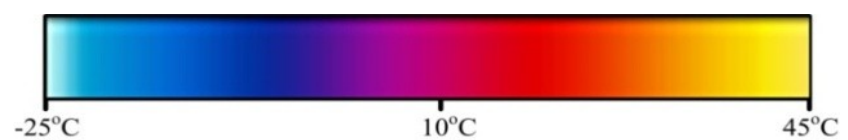

Figure 2: Temperature scale

To classify the distinctive objects, there many various approaches are proposed previously. In this research, for image segmentation a data mining concept of clustering is applied to segment the similar object from image to form groups called clusters. K-Means clustering is simple algorithm and used with a parameter value $(\mathrm{K})$. It used as a segment algorithm with a parameter value 6 to segment the image into six identical regions. The region of interest is segmented based on intensity of color. The location of high temperature will be taken for further analysis to compute wavelength. In the extracted location of high temperature region is observed for distribution of temperature using wavelet transform and the value of region raises, then it can be taken to prediction for forest fire detection.

Image segmentation process is applied for original satellite image shown in Fig 3. Segmented images in the form of clusters are shown in Fig 4. A cluster containing similar objects which distinctive with other cluster.

The whole process of application is implemented using a MATLABR2013a image processing tool box which provide some in-built algorithms, documentations files, object oriented file and tool etc, have useful for application development and also environment supports analysis of data, visualization and computations. From these clusters, location of high temperature region of interest is a feature extracted cluster image shown in Fig.4(F).is selected for detecting forest fire by applying haar wavelet. The haar wavelet [8] is chosen here as it is an efficient technique for decompose the image by levels, where transform coefficient selection decomposition is applied to the image in rows and columns by transforming from data space to wavelet space in frequency domain. The input image is RGB image, after applying haar wavelet transform coefficient selection it can convert into gray scale image.

De-noise the image by applying de-noise technique and decomposed it and present it in two dimensions. 


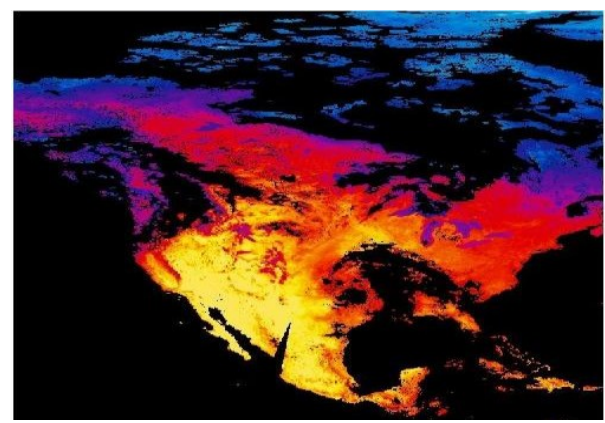

Figure 3: Input image

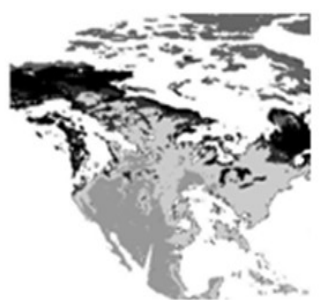

(A)

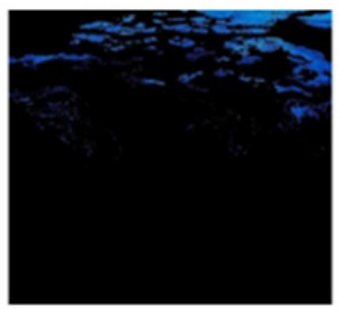

(C)

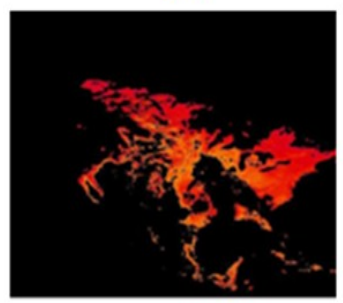

(E)

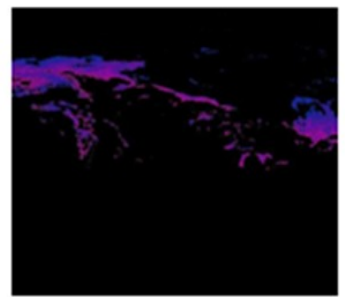

(B)

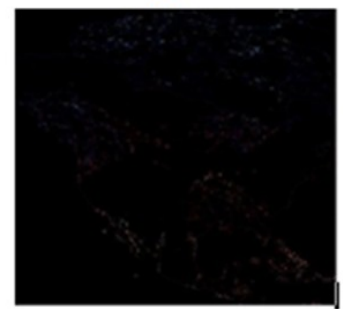

(D)

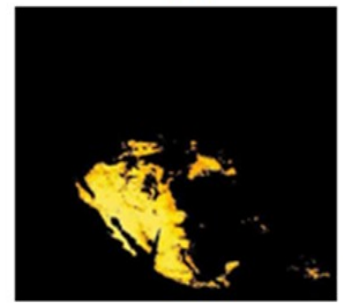

(F)

Figure 4: Temperature image segmented into six clusters (A) Cluster 1 (B) Cluster 2 (C) Cluster 3 (D) Cluster 4 (E) Cluster 5 (F) Cluster 6

In order to detect the forest fire the abnormal temperature distribution is observed from extracted image are identified. The mean wavelength value is to be computed for feature extracted image. In identification of forest fire, the mean wavelength value computed from image is plays a vital role. The research consisting experimentation on 200 images, it is observed that the mean wavelength values for the identification of forest fire are exceeding 31.79. Table I shows, the computed mean wavelengths for the images on existing fire in the forest. Hence, it can be established that whenever the forest fire occurs the computed mean wavelength of the clustered image of interest value is greater than or equals to 31.8 .

\section{Experimental Results}

For researchers, detection of forest fire is most challenging work in present day situation. The identification of forest fire from satellite images is biggest task .Every time we need to segment the satellite image and we have to compute temperature distribution in certain region. In spite of using approaches like smoke velocity distribution, usage of sensors and sounding systems and others, this proposed technique may gives better performance.

The main source of this application is NASA earth observations. The obtained images are used in identification of forest fire by analyzing high temperature distribution in land surface images. In the experimentation, around 200 images are analyzed to compute the success rate of detection. The preliminary 
results shown in Table II comprises of 46 images, represents forest fire or not a forest fire. Consider image 11, its computed mean wavelength is 51.39 this value exceeds the established value of 31.8 . The predicted experimental result is forest fire which is same as historical result. Hence, the prediction is true. Similarly, consider image 29, its computed mean wavelength is 31.74 . The predicted experimental result is no forest fire and also historical result is no forest fire. Hence, the prediction is true. Consider another image 31 its computed mean wavelength value is 31.59 which does not lies in the established range. The predicted experimental result is no forest fire but the historical result is forest fire. Hence, the prediction is false.

Table I. Historically established $\lambda$ for Forest Fire

\begin{tabular}{|c|c|c|}
\hline \hline $\begin{array}{c}\text { Image } \\
\text { Number }\end{array}$ & $\begin{array}{c}\text { Mean wavelength } \\
\text { at level 2 } \\
(\overline{(})\end{array}$ & $\begin{array}{c}\text { Historically established } \\
\text { result }\end{array}$ \\
\hline Image 1 & 45.26 & Forest Fire \\
\hline Image 2 & 54.76 & Forest Fire \\
\hline Image 3 & 51.71 & Forest Fire \\
\hline Image 4 & 50.58 & Forest Fire \\
\hline Image 5 & 44.63 & Forest Fire \\
\hline Image 6 & 46.23 & Forest Fire \\
\hline Image 7 & 56.43 & Forest Fire \\
\hline Image 9 & 56.43 & Forest Fire \\
\hline Image 10 & 48.37 & Forest Fire \\
\hline \hline
\end{tabular}

\section{Conclusion}

This paper presents a method for estimate mean wavelengths of land surface temperature to forest fire and no forest fire for the images obtained from the NASA earth observation satellite. It was demonstrated that the resulting mechanism out performs the methods developed using smoke velocity distribution, sensor methods, and sounding systems. Henceforth, identification of forest fire by making use of clustering and wavelet transform would be an efficient one. The overheads of thermal, radar images can be overcome by the satellite images for the prediction purpose.

Table II. Observation Table

\begin{tabular}{|c|c|c|c|c|}
\hline Image Number & $\begin{array}{c}\text { Mean } \\
\text { Wavelength } \\
\text { (ג) at level 2 }\end{array}$ & $\begin{array}{c}\text { Experimental } \\
\text { view }\end{array}$ & Historical view & Identification \\
\hline Image 11 & 51.39 & Forest Fire & Forest Fire & True \\
\hline Image 12 & 52.41 & Forest Fire & Forest Fire & True \\
\hline Image 13 & 47.42 & Forest Fire & Forest Fire & True \\
\hline Image 14 & 56.4 & Forest Fire & Forest Fire & True \\
\hline Image 15 & 32.83 & Forest Fire & Forest Fire & True \\
\hline Image 16 & 36.71 & Forest Fire & Forest Fire & True \\
\hline Image 17 & 35.14 & Forest Fire & Forest Fire & True \\
\hline Image 18 & 36.04 & Forest Fire & Forest Fire & True \\
\hline Image 19 & 33.73 & Forest Fire & Forest Fire & True \\
\hline Image 20 & 40.04 & Forest Fire & Forest Fire & True \\
\hline Image 21 & 55.85 & Forest Fire & Forest Fire & True \\
\hline Image 22 & 26.78 & Forest Fire & Forest Fire & True \\
\hline Image 23 & 52.64 & Forest Fire & Forest Fire & True \\
\hline Image 24 & 41.34 & Forest Fire & Forest Fire & True \\
\hline Image 25 & 41.29 & Forest Fire & Forest Fire & True \\
\hline Image 26 & 55.15 & Forest Fire & Forest Fire & True \\
\hline Image 27 & 36.35 & Forest Fire & Forest Fire & True \\
\hline Image 28 & 36.39 & Forest Fire & Forest Fire & True \\
\hline Image 29 & 31.74 & No Forest Fire & No Forest Fire & True \\
\hline Image 30 & 46.03 & Forest Fire & Forest Fire & True \\
\hline Image 31 & 31.59 & No Forest Fire & Forest Fire & False \\
\hline Image 32 & 42.22 & Forest Fire & Forest Fire & True \\
\hline Image 33 & 42.88 & Forest Fire & Forest Fire & True \\
\hline Image 34 & 51.33 & Forest Fire & Forest Fire & True \\
\hline Image 35 & 53.43 & Forest Fire & Forest Fire & True \\
\hline Image 36 & 25.02 & No Forest Fire & Forest Fire & False \\
\hline Image 37 & 34.25 & Forest Fire & Forest Fire & True \\
\hline Image 38 & 47.05 & Forest Fire & Forest Fire & True \\
\hline Image 39 & 27.41 & No Forest Fire & Forest Fire & False \\
\hline
\end{tabular}




\begin{tabular}{lcccc} 
Image 40 & 32.48 & Forest Fire & Forest Fire & True \\
Image 41 & 36.27 & No Forest Fire & Forest Fire & False \\
Image 42 & 58.05 & Forest Fire & Forest Fire & True \\
Image 43 & 53.54 & Forest Fire & Forest Fire & True \\
Image 44 & 25.01 & No Forest Fire & Forest Fire & False \\
Image 45 & 54.69 & Forest Fire & Forest Fire & True \\
Image 46 & 54.71 & Forest Fire & Forest Fire & True \\
Image 47 & 43.73 & Forest Fire & Forest Fire & True \\
Image 48 & 49.13 & Forest Fire & Forest Fire & True \\
Image 49 & 52.59 & No Forest Fire & Forest Fire & False \\
Image 50 & 49.24 & Forest Fire & Forest Fire & True \\
Image 51 & 45.07 & Forest Fire & Forest Fire & True \\
Image 52 & 48.24 & Forest Fire & Forest Fire & True \\
Image 53 & 33.89 & No Forest Fire & Forest Fire & False \\
Image 54 & 53.83 & Forest Fire & Forest Fire & True \\
Image 55 & 17.95 & No Forest Fire & No Forest Fire & True \\
Image 56 & 29.59 & No Forest Fire & No Forest Fire & True \\
\hline
\end{tabular}

\section{Future Enhancement}

The present approach is for the identification of forest fires. In spite of this, the area affected with fire is calculated in future. A model can also be developed for identification of forest fire using efficient clustering algorithm to achieve more accuracy.

\section{References}

[1] Turgay Çelik, Hüseyin Ozkaramanli and Hasan Demirel ,"Fire And Smoke Detection Without Sensors: Image Processing Based approach," 15th European Signal Processing Conference (EUSIPCO), Poznan, Poland, 2007, pp 1794-1798.

[2] T. Hame and Y. Rauste, "Multitemporal satellite data in forest mapping and fire monitoring," EARSeL Advanced Remote Sensing, 1995, pp.93-101.

[3] M.D Flannigan and T.H. Vonder Haar, "Forest Fire Monitoring Using Noaa Satellite Avhrr," Candian Journal Of Forest Research., 1986, pp.975-982.

[4] Yasar Guneri Sahin and Turker Ince, "Early Forest Fire Detection Using Radio-Acoustic Sounding System," Sensors, 2009, pp.1485-1498.

[5] Koji Nakau, Masami Fukuda, Keiji Kushida, Hiroshi Hayasaka, Keiji Kimura and Hiroshi Tani "Forest fire detection based on MODIS satellite imagery, and Comparison of NOAA satellite imagery with fire fighters' information," Institute of Low Temperature Science Hokkaido University, Japan, 2005, pp.18-23.

[6] J.L. Casanova, A. Calle, A. Romo and J.Sanz, "Forest Fire Detection And Monitoring By Means of An Integrated MODIS-msg system," Remote Sensing Laboratory of University of Valladolid, 2007, pp.409-413.

[7] K.Angayarkkani and Dr.N.Radhakrishnan,"An Intelligent System For Effective Forest fire Detection using Spatial data," International Journal of Computer Science and Information Security, 2010, pp.202-208.

[8] Radomir S.A Stankovic and Bogdan J. Falkowski, "The Haar Wavelet Transform: Its Status and Achievement," Computers and Electrical Engineering, Elsevier, 2000, pp.25-44.

[9] J. R. Martinez-De Dios and A. Ollero, "Fire Detection And Monitoring Tools For Fire Fighting," International Symposium on Forest Fires, 2004, pp.1-18.

[10] Damir Krstinic, Darko Stipanicev And Toni Jakovcevic, "Histogram-Based Smoke Segmentation In Forest Fire Detection System," International journal of information technology and control, 2009, pp. 237-244.

[11] Wright D.B., T. Yotsumata and N. El-Sheimy, "Real Time Identification And Location Of Forest Fire Hotspots From GeoReferenced Thermal Images," International Society for Photogrammetry and Remote Sensing, 2012, pp.1-6.

[12] Jerome Vicente and Philippe Guillemant, "An image processing technique for automatically detecting forest fire," International Journal of Thermal Sciences, 2002, pp.1113-1120

[13] Junguo Zhang, Wenbin LI, Ning Han, Jiangming Kan,"Forest fire detection system based on a ZigBee wireless sensor network," Higher Education Press and Springer-Verlag, 2008, pp.369-374.

[14] Nuria Utande Gonzalez de la Higuera and Juan Carlos Garcia Seco,"Software fires detection and extinction for forest," International Journal of Interactive Multimedia and Artificial Intelligence, 2008, pp.37-42.

[15] Zhong Zhang, Jianhui Zhao, Dengyi Zhang, Chengzhang Qu, Youwang Ke and Bo Cai," Contour Based Forest Fire Detection Using FFT and Wavelet," International Conference on Computer Science and Software Engineering, 2008, pp. 760-763.

[16] Z. Li, S. Nadon and J. Cihlar," Satellite-based detection of Canadian boreal forest fires: development and application of the algorithm," International Journal of Remote Sensing ,2000, pp.1366-5901.

[17] Suman Tatiraju and Avi Mehta,"Image segmentation using k-means clustering,EM and Normalized cuts," Univercity Of California, 1998.

[18] Khaled Alsabti, Sanjay Ranka and Vineet Singh,” An Efficient K-Means Clustering Algorithm,” The Information Technology Lab (ITL) of Hitachi America Ltd, 2005, pp.1-6.

[19] Siddheswar Ray and Rose H. Turi,” Determination of Number of Clusters in K-Means Clustering and Application in Colour Image Segmentation," Monash Univercity, 2000, pp.30-36.

[20] Narasimha Prasad, Rajkumar Gatadi and B Padmaja" Monitoring and Extracting Abnormalities in Land Surface Temperature Images for Automatically Identification of Forest Fires,” European Modelling Symposium 2013. 